\title{
Erratum to: Use of Fentanyl in Adolescents with Clinically Severe Obesity Undergoing Bariatric Surgery: A Pilot Study
}

\author{
Janelle D. Vaughns ${ }^{1}$ - Victoria C. Ziesenitz ${ }^{2,3,6}$ - Elaine F. Williams ${ }^{2}$ • \\ Alvina Mushtaq ${ }^{2}$ - Ricarda Bachmann ${ }^{4}$ - Gisela Skopp ${ }^{4} \cdot$ Johanna Weiss $^{3}$. \\ Gerd Mikus ${ }^{3} \cdot$ Johannes N. van den Anker ${ }^{2,5,6}$
}

Published online: 16 March 2017

(c) Springer International Publishing Switzerland 2017

\section{Erratum to: Pediatr Drugs \\ DOI 10.1007/s40272-017-0216-6}

An Online First version of this article was made available online at http://link.springer.com/journal/40272/ onlineFirst/page/1 on 25 February 2017. An omission was subsequently identified in the article, and the following correction should be noted:

In Page 6, Acknowledgements: The following text should be included: "Janelle Vaughns, Elaine Williams and Johannes van den Anker were supported by an NIH Grant (5T32HD087969) to conduct this study."

The online version of the original article can be found under doi:10. 1007/s40272-017-0216-6.

Victoria C. Ziesenitz

Ziesenitz.md@gmail.com

1 Division of Anesthesiology, Sedation and Perioperative Medicine, Children's National Health System, Washington, DC, USA

2 Division of Pediatric Clinical Pharmacology, Children's National Health System, Washington, DC, USA

3 Department of Clinical Pharmacology and Pharmacoepidemiology, University of Heidelberg, Heidelberg, Germany

4 Institute of Legal and Traffic Medicine, University of Heidelberg, Heidelberg, Germany

5 Intensive Care and Department of Pediatric Surgery, Erasmus Medical Center, Sophia Children's Hospital, Rotterdam, The Netherlands

6 Division of Paediatric Pharmacology and Pharmacometrics, University of Basel Children's Hospital, 4056 Basel, Switzerland 